\title{
DESAIN SISTEM CETAK KARTU TANDA MAHASISWA UNIVERSITAS MERDEKA MALANG
}

\author{
Heris Pamuntjar, Ir., MT. \\ Fakultas Teknologi Informasi, Universitas Merdeka Malang \\ heris.pamuntjar@unmer.ac.id
}

\begin{abstract}
Student Identity Card ( KTM ) is valid evidence of membership of a student as an active student at a university. Therefore making the KTM should always use renewable integrated the data into a database system where the database contains related information on personal data of students, academic, and financial resources of the student. Thus the KTM function not only as a sign of an active student but pointed at the conclusion of financial transactions of students in each semester. To make the process of making the effectiveness KTM, at the Malang Merdeka University designing automation applications where these applications are connected to the central database that will check the completeness of all data and dependents of students before the students made a KTM. If all requirements are met, students stay in place and KTM photos can be directly printed on a special machine ID Card available.
\end{abstract}

\section{Keywords : system information, automation, student database, KTM, ID Card}

\section{PENDAHULUAN}

Perkembangan

teknologi informasi sangatlah pesat dibanding dengan beberapa tahun silam. Kebutuhan untuk memperoleh informasi dan menggunakannya merupakan hal yang harus diakomodir dengan cepat dan akurat. Oleh karena itu sistem informasi juga harus diterapkan sampai pada proses penyediaan dan pembuatan KTM. KTM merupakan alat bukti keanggotaan sah seorang mahasiswa sebagai mahasiswa aktif pada sebuah universitas. Oleh karena itu pembuatan KTM harus selalu menggunakan data terbaharui yang terintegrasi dalam sebuah sistem database dimana database tersebut mengandung informasi yang saling terkait pada data pribadi mahasiswa, akademik, dan keuangan dari mahasiswa tersebut. Dengan demikian fungsi KTM tidak hanya sebagai tanda mahasiswa aktif namun menunjuk pada terselesaikannya transaksi keuangan dari mahasiswa pada setiap semesternya.

Untuk menjadikan proses pembuatan KTM yang efektif, di Universitas Merdeka Malang Prinsip utamanya adalah pengaturan data/ arsip. Dan tujuan utamanya adalah kemudahan dan kecepatan dalam pengambilan kembali data/arsip. Basis data dikelola/ditangani menggunakan komputer.

Secara lebih lengkap, pemanfaatan basis data dapat dilakukan untuk memenuhi sejumlah tujuan (obyektif) seperti berikut ini : merancang aplikasi otomasi dimana aplikasi tersebut terhubungan pada pusat database yang akan mengecek kelengkapan semua data dan tanggungan mahasiswa sebelum mahasiswa dibuatkan KTM. Bila semua syarat sudah terpenuhi, mahasiswa tinggal foto ditempat dan KTM dapat langsung dicetak pada mesin khusus ID Card yang tersedia.

\section{Kajian Pustaka}

Basis data dapat didefinisikan dalam sejumlah sudut pandang seperti :

a. Himpunan kelompok data (arsip yang saling berhubungan yang diorganisasi sedemikian rupa agar kelak dapat dimanfaatkan kembali dengan cepat dan mudah.

b. Kumpulan data yang saling berhubungan yang disimpan secara bersama sedimikian rupa dan tanpa pengulangan (redundansi) yang tidak perlu, untuk memenuhi berbagai kebutuhan .

c. Kumpulan file/tabel/arsip yang saling berhubungan yang disimpan dalam media penyimpanan elektronis. a. Kecepatan dan kemudahan (Speed)

Pemanfaatan basis data memungkinkan kita untuk dapat menyimpan data atau melakukan perubahan/ manipulasi terhadap data atau menampilkan kembali data tersebut dengan lebih cepat dan mudah daripada dengan cara manual.

b. Efisiensi Ruang Penyimpanan (Space) 
Dengan basis data, optimalisasi penggunan ruang penyimpanan dapat dilakukan, karena kita dapat melakukan penekanan jumlah redundansi data, baik dengan menerapkan sejumlah pengkodean atau dengan membuat relasi-relasi (dalam bentuk file) antar kelompok data yang saling berhubungan.

\section{c. Keakuratan (Accuracy)}

Pemanfaatan pengkodean atau pembuatan relasi antar data bersama dengan penerapan aturan atau batasan (constraint) tipe data, domain data, keunikan data, dan sebagainya, yang secara ketat dapat diterapkan dalam sebuah basis data, sangat berguna untuk menekan ketidakakuratan penyimpanan data.

d. Ketersediaan (availability)

Kita harus dapat memilah adanya data utama / master / referensi, data yang sudah jarang atau bahkan tak pernah lagi kita gunakan, dapat kita atur untuk dilepaskan dari sistem basis data yang sedang aktif (menjadi off-line) ke media penyimpanan off-line karena kepentingan pemakaian data, sebuah basis data dapat memiliki data yang disebarkan dibanyak lokasi geografis.

\section{e. Kelengkapan (completeness)}

Lengkap / tidaknya data yang kita kelola dalam sebuah basis data bersifat relatif (baik terhadap kebutuhan pemakai maupun terhadap waktu). Dalam sebuah basis data disamping data kita juga harus menyimpan struktur (baik yang mendefinisikan obyek-obyek dalam basis data maupun definisi detail dari tiap obyek, seperti struktur file / tabel atau indeks), untuk mengakomodasikan kebutuhan kelengkapan data yang semakin berkembang, maka kita tidak hanya dapat menambah record data, tetapi juga menambah struktur dalam basis data, baik penambahan obyek baru (tabel) atau dengan penambahan field baru pada suatu tabel.

f. Keamanan (security)

Memang ada sejumlah sistem (aplikasi) pengelola basis data yang tidak menerapkan aspek keamanan dalam penggunaan basis data. Tetapi untuk sistem yang besar dan serius, aspek keamanan juga dapat diterapkan dengan ketat. Dengan begitu kita dapat menentukan siapa-siapa (pemakai) yang boleh menggunakan basis data beserta obyek-obyek didalamnya dan menentukan jenis-jenis operasi apa saja yang boleh dilakukannya. g. Kebersamaan pemakaian (sharability)

Pemakai basis data tidak terbatas pada satu pemakai saja, data pegawai dalam basis data kepegawaian, misalnya, dapat digunakan oleh banyak pemakai atau oleh banyak sistem (sistem penggajian, sistem akuntansi, dan sebagainya).

\section{HASIL DAN PEMBAHASAN}

Berikut ini adalah hasil implementasi dari aplikasi KTM Maker

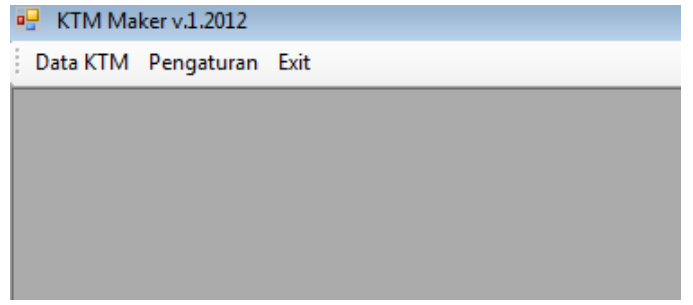

Gambar 1. Tampilan menu

Agar hasil cetak KTM tampil dengan baik, maka perlu penyesuaian batas-batas margin dan ukuran yang sesuai dengan ID Card yang disediakan. Selain itu perangkat lunak perlu dihubungkan ke pusat bank data dengan mengatur alamat IP server, user, password, nama database dan tabel yang terkoneksi. Hal tersebut merupakan hak privasi dari administrator program. Sedangkan pengguna hanya mengatur lokasi penyimpanan foto hasil capture, margin dan size.

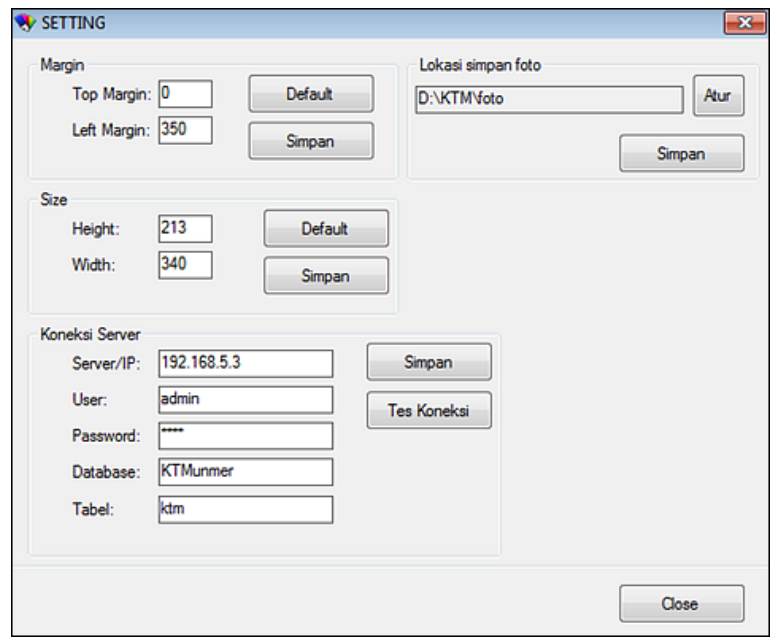

Gambar 2. Pengaturan untuk gambar dan server database 
Setelah menu Data KTM dijalankan maka akan ditampilkan antarmuka pembuatan KTM

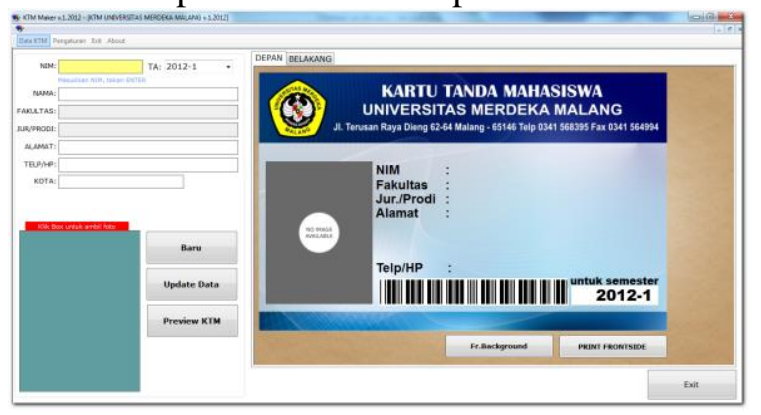

Gambar 3. Tampilan antarmuka kosong pembuatan KTM

Pada saat user memasukkan Nomor Induk Mahasiswa jika ada, maka data mahasiswa akan ditampilkan. Jika data sudah memiliki foto sebelumnya, maka foto secara otomatis akan ditampilkan.

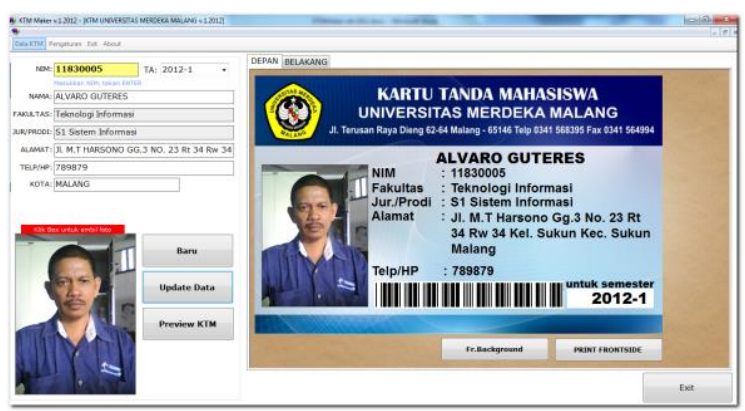

Gambar 4. KTM dengan data mahasiswa

Untuk mengambil foto mahasiswa, perangkat lunak ini dapat menggunakan web camera. Pada perangkat lunak disediakan pemilihan atau pengaturan kamera yang sedang online atau aktif terhubung pada PC atau komputer yang sedang digunakan untuk proses pembuatan KTM saat itu.

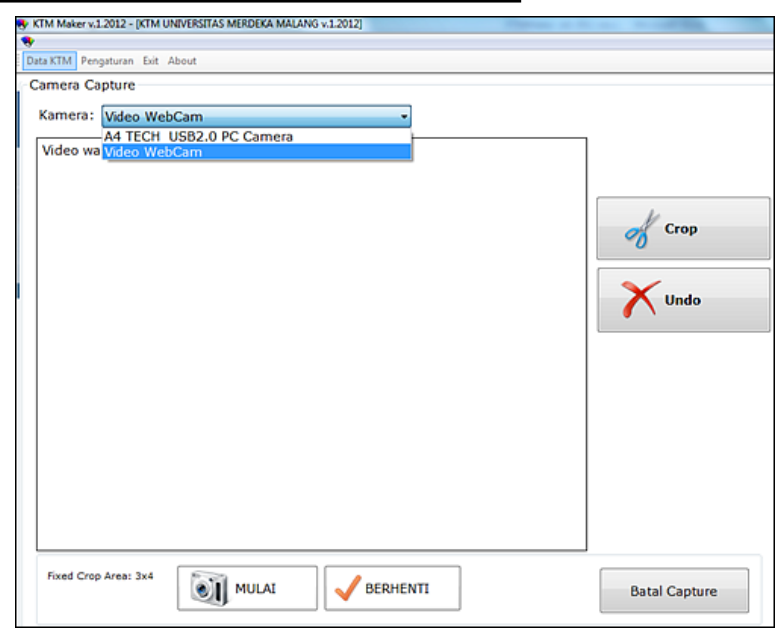

Gambar 5. Pemilihan kamera untuk camera capture

User dapat menekan tombol Mulai untuk menampilkan gambar berupa video hasil yang ditangkap dari kamera. Sampai proses ini gambar belum berupa foto yang tersimpan. Petugas masih haris mengatur posisi dari badan atas mahasiswa.

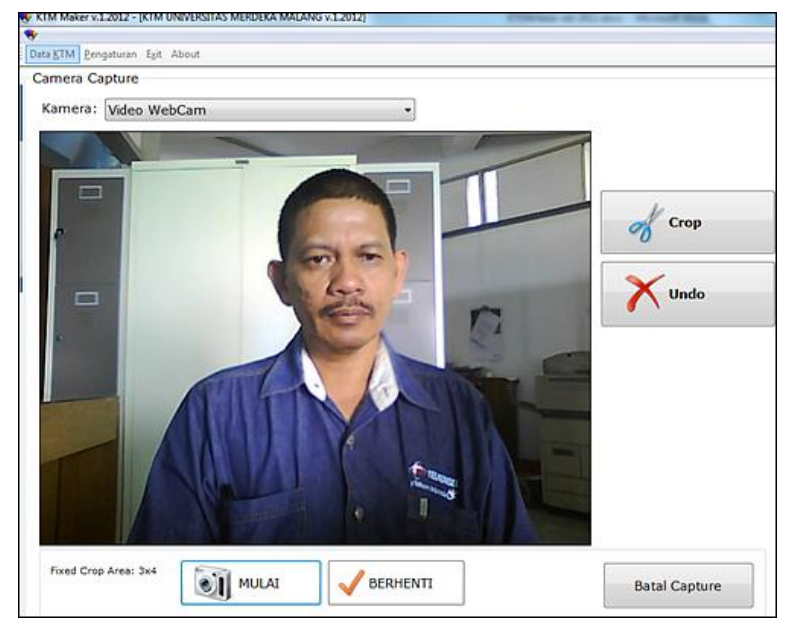

Gambar 6. Tampilan saat kamera berhasil menangkap gambar

Setelah posisi dirasa cukup baik, petugas menekan tombol berhenti untuk menyimpan sementara hasil capture. Setelah itu petugas melakukan proses cropping yang otomatis berdimensi $4 \times 6$ pada bagian foto yang ingin ditampilkan pada KTM. 


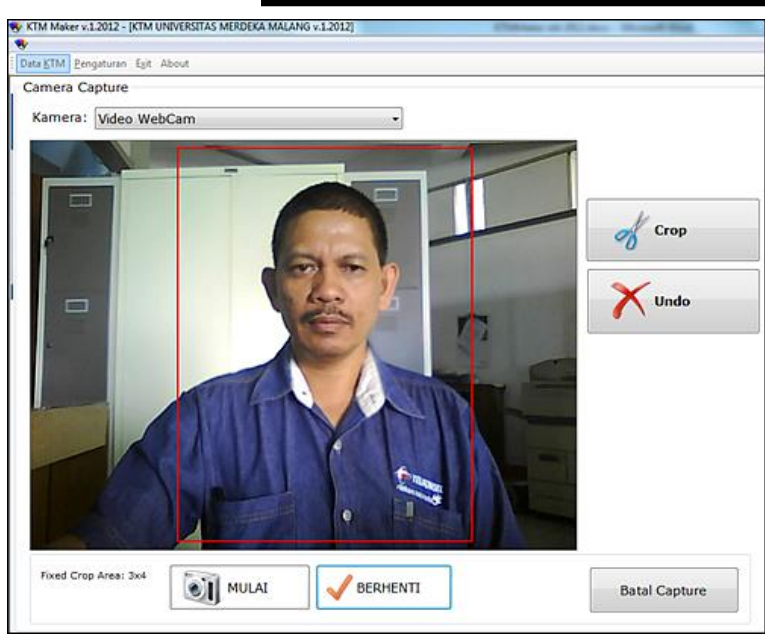

Gambar 7. Proses cropping

Gambar hasil cropping akan diberi nama sesuai NIM dari mahasiswa yang bersangkutan. Sehingga pada saat NIM tersebut dipanggil pada form, maka data dan foto sekalian akan tampil.

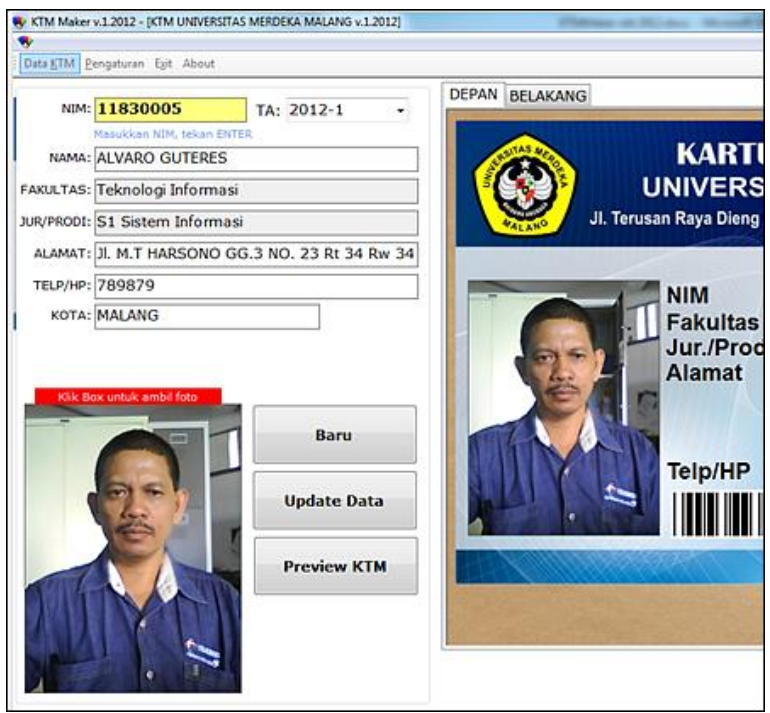

Gambar 8. Hasil cropping

Untuk mengganti gambar latar dari KTM, petugas dapat menggantinya sesuai kebutuhan pada tombol Fr. Background untuk latar depan, Bk. Background untuk latar halaman belakang.

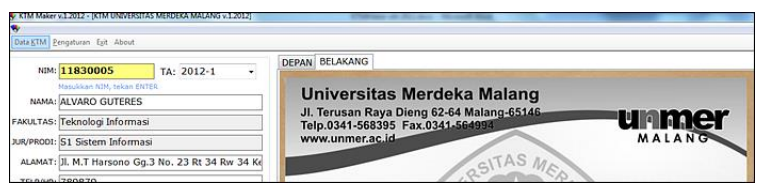

Gambar 9. Gambar bagian belakang KTM

Proses mencetak KTM dilakukan dengan menekan tombol Print Frontside untuk cetak sisi depan, Print Backside untuk cetak sisi baliknya.

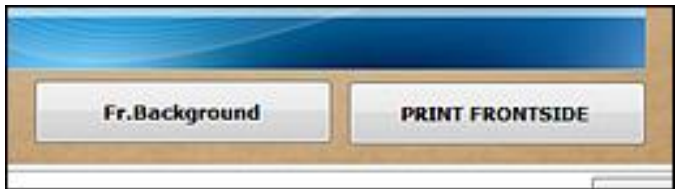

Gambar 10. Tombol untuk cetak

\section{KESIMPULAN}

1. Dengan adanya Sistem Cetak Kartu Tanda Mahasiswa yang dirancang ini diharapkan fungsi KTM sebagai tanda mahasiswa aktif dan pengecekan informasi tanggung jawab keuangan mahasiswa dapat tercapai dan tepat sasaran.

2. Dengan adanya perangkat lunak ini, pembuatan KTM yang terintegrasi dengan database menjadikan isi KTM menjadi akurat dan lengkap

3. Dengan adanya perangkat lunak ini pembuatan KTM dapat dibuat dengan cepat.

\section{REFERENSI}

[1] Rod Stephens, "Visual Basic 2010 Programmer's Reference", Wiley, Indiana, 2010

[2] http://www.idautomation.com

[3] http://www.aforgenet.com/framework

[4] Steven Holzner, "Visual Basic .NET Black Book”, Paraglyph Press, Arizona, 2002 